\title{
Studi Perbandingan Kinerja Pier Jembatan Tipe Portal dengan Tipe Dinding
}

\author{
Ibnu Pudji Rahardjo ${ }^{1, *}$, Chomaedhi ${ }^{1}$, Yudnina Hanifah ${ }^{1}$ \\ Departemen Teknik Infrastruktur Sipil, Institut Teknologi Sepuluh Nopember, Surabaya ${ }^{1}$ \\ Koresponden*, Email: ibnupudji@gmail.com
}

\begin{tabular}{lll}
\hline & Info Artikel & Abstract \\
\hline Diajukan & $31 \mathrm{Mei} 2019$ & $\begin{array}{l}\text { Seismic performance analysis is important to conduct in order to determine structural } \\
\text { performance during an earthquake. The result of this analysis in one of the parameters that } \\
\text { Delperbaiki }\end{array}$ \\
hisgineers to make decisions in structural design. Is the level of structural performance \\
satisfying or should structural retrofit be done? In this study, structural performance analysis \\
was carried out on two pier design models which will be applied to Pasuruan-Probolinggo toll \\
road project. The first pier is a wall and the other pier is a pillar. The analysis was carried out \\
\end{tabular}

\begin{abstract}
Abstrak
Analisa peforma strukur terhadap gempa penting untuk diperiksa untuk mengetahui kinerja struktur saat terjadi gempa. Hasil dari analisis ini merupakan salah satu parameter dalam pengambilan keputusan desain struktur. Apakah level kinerja struktur sudah sesuai dengan yang diharapkan atau perlukah tahap retrofit struktur. Dalam studi ini analisa peforma struktur dilakukan terhadap dua model desain pier yang akan digunakan dalam proyek tol Pasuruan-Probolinggo. Pier pertama merupakan pier tipe dinding serta pier lainnya adalah pier tipe portal. Analisa dilakukan sesuai dengan pedoman ATC-40 dengan menginputkan karakteristik kenonlineran struktur. Hasil analisa menunjukkan bahwa level kinerja pier tipe portal adalah DC-LS sedangkan pier tipe dinding adalah DC. Pier tipe portal mempunyai daktilitas yang hampir sama dengan pier tipe dinding, base shear yang diterima pier tipe portal lebih kecil dibandingkan base shear yang diterima pier tipe dinding. Deformasi terjadi pada pier portal lebih besar daripada deformasi pada pier dinding.
\end{abstract} sruktur

\section{Pendahuluan}

Jalan tol Pasuruan-Probolinggo dalam salah satu sectionnya, memiliki dua alternatif desain tipe pier yakni dinding seperti terlihat pada Gambar 1 dan portal seperti terlihat pada Gambar 3. Pier tipe portal didesain dengan faktor reduksi $1(\mathrm{R}=1)$ untuk struktur pondasi serta $\mathrm{R}=5$ untuk struktur atas arah melintang dan $\mathrm{R}=3$ arah memanjang. Sementara itu, pier tipe dinding didesain dengan $\mathrm{R}=3$ untuk struktur pondasi serta $\mathrm{R}=5$ untuk struktur atas arah melintang dan $\mathrm{R}=3$ arah memanjang. Dari hasil analisis linear sesuaian dengan RSNI 1726:2016 [2] dengan faktor reduksi tersebut didapatkan jumlah tiang pancang. Pier tipe portal dengan $\mathrm{R}=1$ untuk pondasi jumlah tiangnya $6 \times 6$ seperti yang ditunjukkan pada Gambar 2 sedangkan pier tipe dinding degan $\mathrm{R}=3$ untuk pondasi, jumlah tiang pancangnya $4 \times 5$ seperti yang ditunjukkan pada Gambar 4.

Untuk mengetahui level kinerja struktur terhadap gempa dilakukanlah analisa kinerja. Hasil dari analisa kinerja dapat menjadi bahan pertimbangan dalam pemilihan model desain.
Salah satu tipe analisa kinerja struktur yang saat ini sering digunakan karena dinilai dapat menggambarkan dengan akurat perilaku struktur saat dibebani adalah peformance based design.

Analisis statik nonlinear pushover merupakan komponen performance based design yang menjadi sarana dalam mencari kapasitas dari suatu struktur. Dasar analisis dilakukan dengan peningkatan beban statik tertentu dalam arah lateral yang nilainya ditingkatkan berangsur-angsur (incremental) secara proporsional pada struktur hingga mencapai target displacement atau mencapai mekanisme diambang keruntuhan [5]. Tujuan dalam analisis pushover adalah untuk memperkirakan gaya maksimum dan deformasi yang terjadi[3]. ATC-40[2] mendefinisikan kriteria-kriteria struktur tahan gempa adalah sebagai berikut

1. Immediate Occupancy (IO) Bila gempa terjadi, struktur mampu menahan gempa tersebut, struktur tidak mengalami kerusakan struktural dan tidak mengalami kerusakan non structural sehingga dapat langsung dipakai. 
2. Life Safety (LS) Bila gempa terjadi, struktur mampu menahan gempa, dengan sedikit kerusakan struktural, manusia yang tinggal/berada pada bangunan tersebut terjaga keselamatannya dari gempa bumi.

3. Collapse Pervention (CP) Bila gempa terjadi, struktur mengalami kerusakan struktural yang sangat berat, tetapi belum runtuh.

4. Structural Stability (SS) adalah kondisi dimana struktur telah mengalami kerusakan parsial ataupun total, kerusakan yang terjadi telah menyebabkan degradasi kekuatan dan kekakuan pada sistem penahan gaya lateral.

Selain level kinerja struktur, perlu juga diperhatikan daktilitas struktur. Daktilitas adalah kemampuan struktur gedung untuk mengalami simpangan pasca-elastik yang besar secara berulang kali dan bolak-balik akibat beban gempa di atas beban gempa yang menyebabkan terjadinya pelelehan pertama, sambil mempertahankan kekuatan dan kekakuan yang cukup, sehingga struktur gedung tersebut tetap berdiri, walaupun sudah berada dalam kondisi di ambang keruntuhan. Faktor daktilitas adalah rasio antara simpangan maksimum struktur gedung pada saat mencapai kondisi di ambang keruntuhan dan simpangan struktur gedung pada saat terjadinya pelelehan pertama di dalam struktur gedung [2].

\section{Pemodelan Struktur}

Struktur dimodelkan secara 3D menggunakan program SAP2000. Material yang digunakan adalah beton fc' $30 \mathrm{mPa}$ serta baja tulangan $240 \mathrm{mPa}$ untuk $\mathrm{D}<13$ dan $400 \mathrm{mPa}$ untuk $\mathrm{d}>13$. Desain awal jembatan terdiri dari 4 bentang dengan 3 portal tipe dinding. Sementara itu, redesain jembatan terdiri dari 3 bentang dengan 2 pier tipe portal.
Selain itu untuk memodelkan faktor penahan pada tanah yang bekerja melawan gaya luar, tanah diasumsikan memiliki pegas. Pegas ini dinamakan koefisien reaksi tanah dasar (coefficient of subgrade reaction) yang dapat diperoleh dari modulus perubahan bentuk (deformasi) tanah pondasi [4]. Dalam studi ini, interaksi tanah dengan struktur dimodelkan dengan konstanta pegas (spring constant) bersesuaian dengan metode Nakazawa.

\section{Metode Analisa Peforma Struktur}

Analisa kinerja struktur dilakukan menggunakan fasilitas pushover yang terdapat pada SAP2000. Kekuatan bahan ultimate, parameter P- $\Delta$ serta sendi plastis diinputkan kedalam pemodelan untuk mendesripsikan karakteristik nonlinear bahan, geometris serta penampang. Dalam analisa kinerja, diperlukan kurva kapasitas yang menunjukan fungsi base shear terhadap displacement.

Kurva kapasitas ini kemudian diplotkan terhadap kurva respons spectrum dalam satuan SA-SD. Kurva hasil plot tersebut disebut dengan kurva ADRS (Acceration Displacement Response Spectra) Response spektrum yang akan diplot bersama dengan kurva kapasitas dapat dilihat pada Gambar 6. Titik kinerja (Performance Point) dari struktur dapat diketahui titik potong kedua kurva tersebut.

Analisa pushover dilakukan terhadap model 3D pier tipe portal serta portal tipe dinding. Sendi plastis dimodelkan pada ujung ujung frame portal dimana terjadi momen maksimum akibat beban gempa. Sendi plastis juga dimodelkan pada pondasi per 1 meter mengingat posisi momen maksimum terjadi akibat gempa pada tiang tertanam bergeser sepanjang tiang. Karakteristik sendi plastis ini ditentukan oleh 'Auto PM2-M3' untuk kolom pada SAP2000.

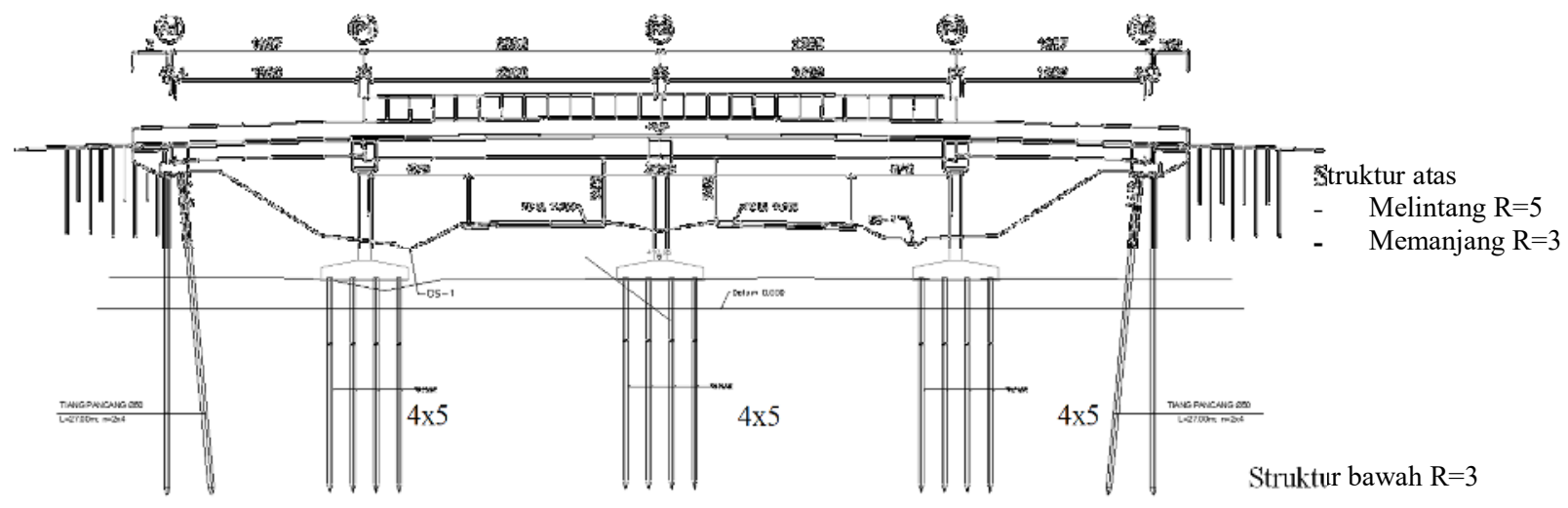

Gambar 1. Potongan Melintang Struktur Jembatan dengan Pier Dinding 


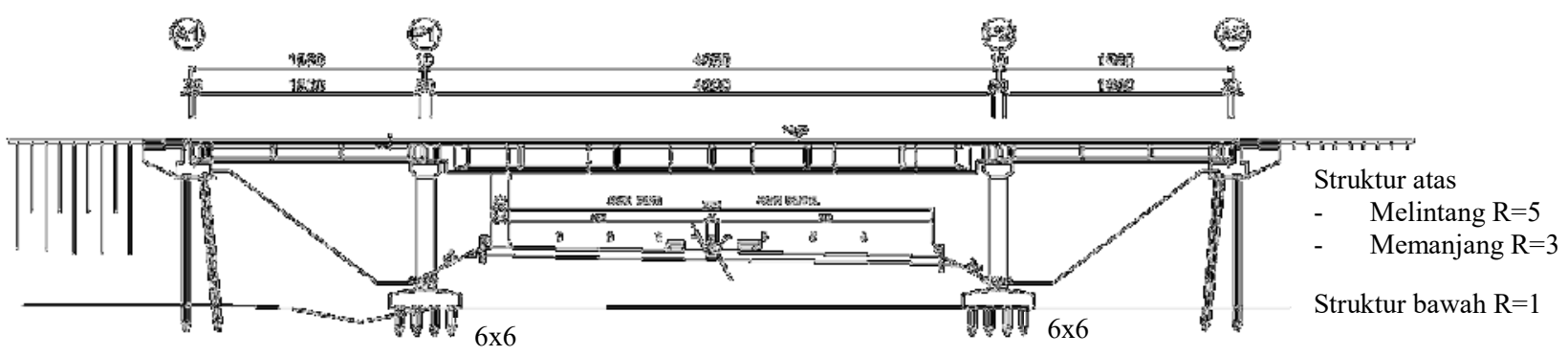

Gambar 2. Potongan Melintang Struktur Jembatan dengan Pier Portal
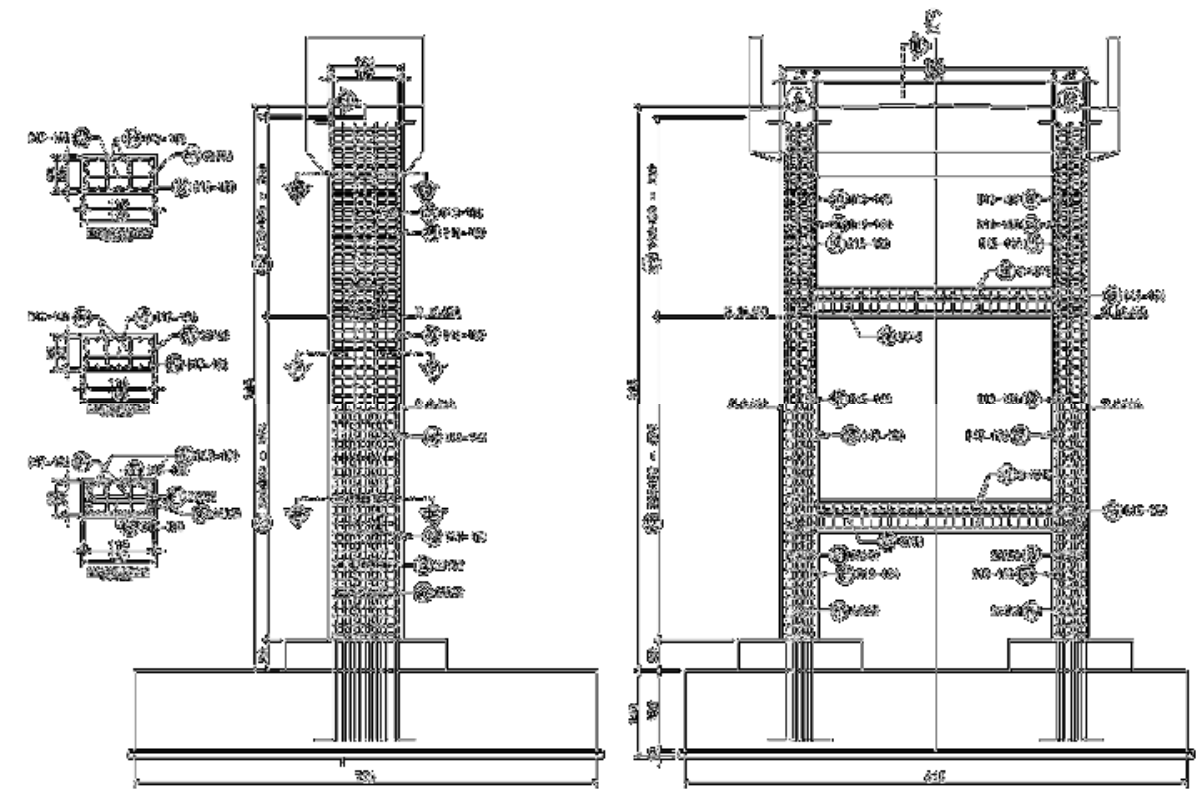

Gambar 3. Detail Pier Portal
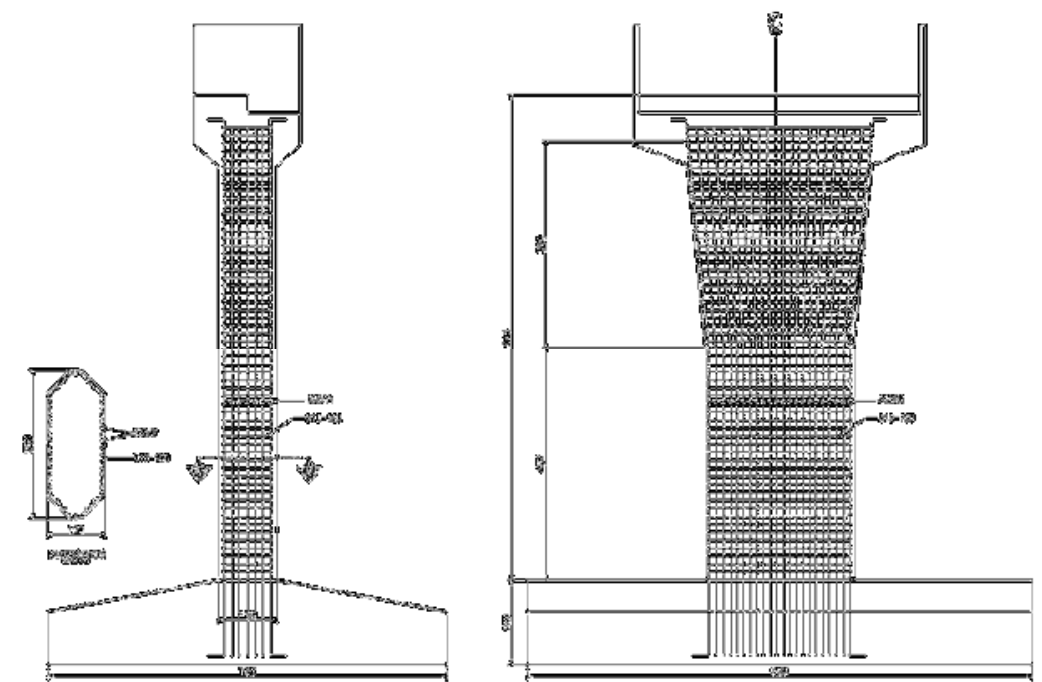

Gambar 4. Detail Pier Dinding 


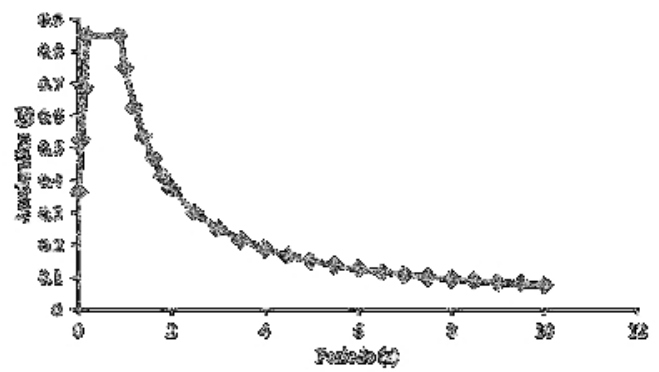

Gambar 5. Respons Spektrum Gempa Sumber: Hasil analisis berdasarkan SNI 1726-2016

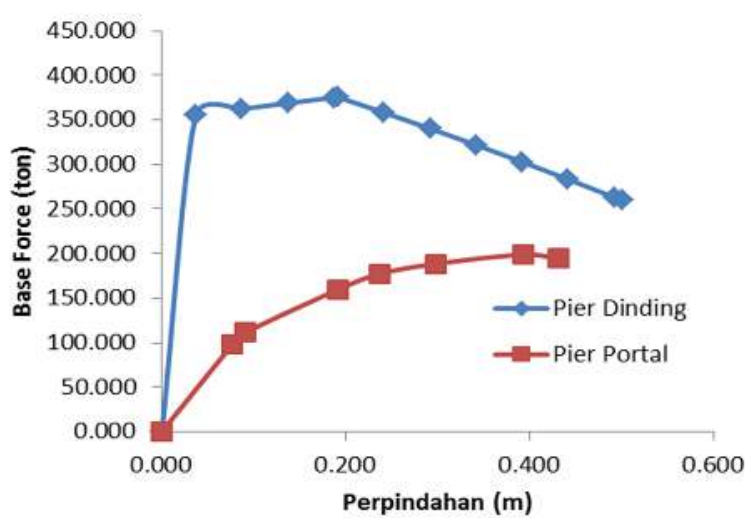

Gambar 6. Kurva Kapasitas Pier Dinding dan Pier Portal Sumber: Hasil analisis

\section{Hasil dan Pembahasan}

Dari analisa statik pushover didapatkan kurva kapasitas untuk masing-masing tipe pier seperti yang tergambar dalam Gambar 7. Dari kurva tersebut dapat dihitung daktilitas pier

- Pier tipe portal $=0.3934 / 0.0770=5.104$

- Pier tipe dinding $=0.1910 / 0.0373=5.121$

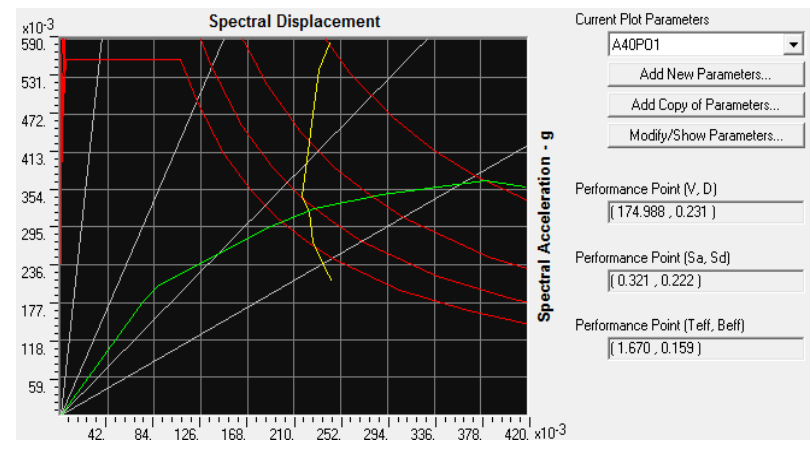

Gambar 7. Performance Point Pier Portal

Sumber: Hasil analisis sesuai dengan ATC-40

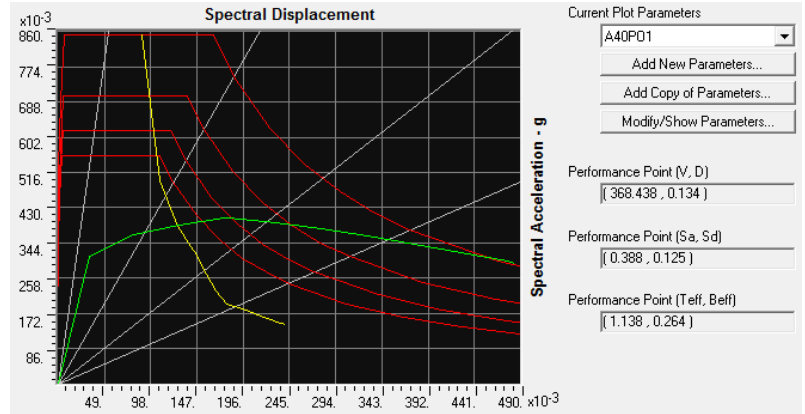

Gambar 8. Performance Point Pier Dinding

Sumber: Hasil analisis sesuai dengan ATC-40

Selain kurva kapasitas didapatkan pula performance point yang dihasilkan dari perpotongan kurva kapasitas dan respons spectrum. Perpotongan ini dapat menunjukkan base shear dan deformasi struktur saat terjadi gempa. Diketahui dari Gambar 6 dan Gambar 7 bahwa deformasi yang terjadi pada pier portal lebih besar dari pada deformasi yang terjadi pada pier dinding. Berdasarkan ATC-40, nilai deformasi ini kemudiaan menjadi acuan untuk menghitung level kinerja struktur.

Tabel 1. Level Kinerja Struktur berdasarkan ATC-40

\begin{tabular}{ccccc}
\hline \multirow{2}{*}{ Level Kinerja } & \multicolumn{4}{c}{ Simpangan Lantai } \\
\cline { 2 - 5 } & IO & DC & LS & SS \\
\hline Drift Ratio & 0.01 & $0.01-0.02$ & 0.02 & $0.03 \mathrm{~V} / \mathrm{S}$ \\
\hline
\end{tabular}

- Pier tipe portal $=0.231 \times 100 / 9.15=2.52 \%$, Level Kinerja DC-LS

- Pier tipe dinding $=0.134 \times 100 / 9.15=1.46 \%$, Level Kinerja DC

Informasi penting lainnya yang didapatkan adalah berapa base shear yang diterima struktur saat terjadi gempa, lihat Gambar 6 dan Gambar 7. Base shear erat kaitannya dengan massa struktur dimana semakin berat struktur maka semakin besar pula base shear yang diterima. Dari perbadingan kurva kapasitas, dapat dilihat tipe pier portal yang ramping menerima base shear lebih kecil dari pada tipe pier dinding yang massif. Nilai base shear ini akan menentukan jumlah dan konfigurasi tiang. Umumnya, jumlah kebutuhan tiang linear dengan besarnya base shear.

Pada studi ini base shear pada pier dinding yang masif lebih besar daripada base shear pier portal yang ramping. Seharusnya jumlah kebutuhan tiang pancang pier dinding lebih banyak dari pada pier portal. Namun, desainer struktur pier dinding menggunakan faktor reduksi yang cukup besar 
yakni 3 sehingga base shear yang diterima struktur adalah $1 / 3$ kali base shear sesungguhnya. Hal ini mempengaruhi kebutuhan jumlah tiang.

\section{Simpulan}

Studi ini membandingkan level kinerja dan daktilas dua alternatif desain pier pada Proyek Jalan Tol ProbolinggoPasuran. Kedua alternatif desain tersebut direncanakan bersesuaian dengan SNI 1726-2016 dengan wilayah gempa Pasuruan. Dari analisis pushover yang dilakukan berdasarkan ATC-40, diketahui bahwa tipe pier portal memliki daktilitas yang hamper mirip dengan tipe pier dinding. Perbedaannya terdapat pada perpotongan kurva kapasitas dan response spectrum. Dari perpotongan ini, diketahui bahwa level kinerja pier tipe portal yakni antara DC dan LS sedangkan level kinerja pier tipe dinding yakni DC.

Baik level kinerja, daktilitas dan base shear berperan penting dalam desain struktur. Perencana dan owner harus mempertimbangkan faktor-faktor ini dalam pengambilan keputusan.

\section{Daftar Pustaka}

[1] Applied Technology Council (ATC), "ATC40 Seismic Evaluation and Retrofit of Concrete Buildings Volume I" California, 1996.

[2] Badan Standarisasi Nasional (BSN), "Standar Perencanaan Ketahanan Gempa Untuk Struktur Bangunan Gedung" Bandung, 2002

[3] Dewobroto, Wiryanto, "Evaluasi Kinerja Struktur Baja Tahan Gempa dengan Analisa Pushover". Banten : Program Studi Teknik Sipil Fakultas Teknik Universitas Pelita Harapan Indonesia, 2005.

[4] Sosrodarsono, Suyono, dan Nakazawa, Kazuto, Mekanika Tanah dan Teknik Pondasi, Jakarta: Pradnya Paramita, 2000.

[5] Wisnumurti, Cahya, I, Anas, A, "Analisis Pushover pada Gedung tidak Beraturan dengan Study Kasus pada Gedung Baru FIA Unibraw" Journal Rekayasa Sipil. ISSN 1978-5658 (2):11-22. 2008. 
